\title{
Molecular Genetic Variations and Phylogenetic Relationship Using Random Amplified Polymorphic DNA of three species of Catfishes (Family: Schilbidae) in Upper Egypt
}

\author{
Abu-Almaaty, A. H. ${ }^{1}$; Abdel-Basset M. Ebied ${ }^{2}$ and Mohammad allam ${ }^{3}$ \\ 1- Zoology Department, Faculty of science, Port Said University, Egypt. \\ 2, 3 Cytogenetic Laboratory-Zoology Department- Faculty of Science (Qena) - South Valley University, Egypt
}

\begin{abstract}
The RAPD-PCR analysis was carried out on three species of fresh water fishes of family Schilbidae (Schilbe mystus, Schilbe uranoscopus and Siluranodon auritus) by using twenty primers. All twenty primers amplified successfully on the genomic DNA extracted from all studied fish species. The number of bands was variable in each species. Schilbe mystus produced number of bands 174, and Schilbe uranoscopus 193, while in Siluranodon auritus 210 bands. A total of 295 DNA bands were generated by all primers in all specimen, out of these DNA bands 97 (32.88\%) were conserved among all specimens, while 198 bands were polymorphic with percentage $67.12 \%$ of all the twenty tested primers produced polymorphism in all specimens table 22 . These results are discussed in relation to implications of RAPD assays in the evaluation of genetic diversity.

Key words: Genetics - Molecular genetics - Schilbidae, random amplified polymorphic DNA, RAPD, fingerprinting, primer, genetic diversity and Upper Egypt.
\end{abstract}

\section{Introduction}

The history of molecular genetics goes back to early 1950 when F. Crick, J. Watson and M. Wilkins established the currently accepted model of DNA structure (the double helix). This was a Nobel Prize winning discovery in Chemistry Hallerman $\boldsymbol{e t}$ al. (2003). Since then details of structure and function of DNA and genes have been clarified and started to use in determining the genetic diversity Okumus and Ciftci, (2003).

The development of molecular technologies has provided researchers in many different fields with powerful new tools. Fishes are the most species group of vertebrates, with more than 24,000 species. They are characterized by great diversity in ecology, morphology, life history, behavior and physiology. Fishes range in size from the very small to the very large Le Comber and Smith, (2004). The PCR technique is basically a primer extension reaction for amplifying specific nucleic acids in vitro. The use of a thermostable polymerase referred to as taq allows a short stretch of DNA to be amplified to about a million fold so that one can determine its size, nucleiotide sequence, etc. Ali, (2003). Polymerase chain reaction (PCR) technology has become a widespread research technique and has led to the development of several novel genetic assays based on selective amplification of DNA Erlich, (1989).

The RAPD method is a PCR-based technique that amplifies random DNA fragments with the use of single short primers of arbitrary nucleotide sequence under low annealing conditions, this technique has been extensively used for species classification and microorganism strain determination Bielawski and Pumo, (1997); Bardakci, (2001) and Lee et al. ( 2007).

Bardakci, (2001), reported that, perhaps the main reason for the success of RAPD analysis is the gain of a large number of genetic markers that require small amounts of DNA without the requirement for cloning, sequencing or any other form of the molecular characterization of the genome of the species in question. Weising, (1995), reported that, RAPD markers can be sensitive to changes in reaction conditions, resulting in low reproducibility and inconsistencies in amplification efficiencies among samples. Using RAPD-PCR is very useful in determination genetic molecular variations and relationship degree between the species which belong to same family. Randomly amplified polymorphic DNA-PCR (RAPD-PCR) is a technique widely used for studying the DNA polymorphism between closely related species without the requirement of prior knowledge of the genome (Welsh and McClelland, (1990); Williams et al. (1990) and Zhivotovsky, (1999) ).

Comparatively few studies related strictly to the molecular differences between some species of freshwater fishes and especially Random amplified polymorphic DNA (RAPD) analysis on three species of freshwater fishes in Upper Egypt namely; Schilbe mystus, Schilbe uranoscopus and Siluranodon auritus (Family: Schilbidae- Order: Siluriformes).

The aim of the present study was to using Randomly Amplified Polymorphic DNA-PCR (RAPD - PCR) to study the molecular genetic differences between three species of family Schilbidae, and determination the relationship degree between these species. 


\section{Materials and Methods}

In the present study, three species of fresh water fishes, (Schilbe mystus, Schilbe uranoscopus and Siluranodon auritus) figures (1,2 and 3) family: Schilbidae, were collected from different localities of upper Egypt (Qena and Aswan). The Identification and classification of species were carried out using descriptions and keys provided by Bishai and khalil, (1991) and Mekkawy et al. (2011).

Muscles tissue from fishes immediately after capture, were put on tubes and stored in a freezer until processed for RAPD-PCR analysis. Twenty primers (Operon) were used to amplify genomic DNA. Operon 10mer kits contained 10 base oligonucleotide primers (Table 1) used in this study.

\section{RAPD Reaction:}

DNA extraction using the Qiagen DNeasy (Qiagen Santa Clara, CA). DNA concentration was determined by diluting the DNA 1:5 in $\mathrm{H} 2 \mathrm{O}$. The DNA samples were electrophoresed in 1\% agarose gel against $10 \mathrm{ng}$ of a DNA size marker. This marker covers a range of concentration between $95 \mathrm{ng}$ and $11 \mathrm{ng}$. Thus, estimation of the DNA concentration in a given sample was achieved by comparing the degree of fluorescence of the unknown DNA band with the different bands in the DNA size marker.

A set of twenty primers RAPD (Tables 1) was used. The amplification reaction was carried out in $25 \mu 1$ reaction volume containing $1 \mathrm{X}$ PCR buffer, $1.5 \mathrm{mM} \mathrm{MgCl} 2,0.2 \mathrm{mM}$ dNTPs, $1 \mu \mathrm{M}$ primer, $1 \mathrm{U}$ Taq DNA polymerase and $25 \mathrm{ng}$ template DNA.

Table(1): The sequence of 20 primers using for RAPD analysis of family: Shilbidae A: Adenine, T: Thymine, G: Guanine and C: Cytosine

\begin{tabular}{|c|c|c|c|}
\hline No. & Name of primer & Nucleotide length & Sequence $\left(5^{\prime}-3^{\prime}\right)$ \\
\hline 1 & OPA - 4 & 10-mer & AATCGGGCTG \\
\hline 2 & OP A -7 & 10-mer & GAAACGGGTG \\
\hline 3 & OPA -9 & 10-mer & GGGTAACGCC \\
\hline 4 & OPA -15 & 10-mer & TTCCGAACCC \\
\hline 5 & OPA -17 & 10-mer & GACCGCTTGT \\
\hline 6 & OPB -6 & 10-mer & TGCTCTGCCC \\
\hline 7 & OPB -17 & 10-mer & AGGGAACGAG \\
\hline 8 & OPC -1 & 10-mer & TTCGAGCCAG \\
\hline 9 & OPC -11 & 10-mer & AAAGCTGCGG \\
\hline 10 & OPC -18 & 10-mer & TGAGTGGGTG \\
\hline 11 & OPD-5 & 10-mer & TGAGCGGACA \\
\hline 12 & OPE-5 & 10-mer & TCAGGGAGGT \\
\hline 13 & OPE-6 & 10-mer & AAGACCCCTC \\
\hline 14 & OPE-10 & 10-mer & CACCAGGTGA \\
\hline 15 & OPF-6 & 10-mer & GGGAATTCGG \\
\hline 16 & OPG-2 & 10-mer & GGCACTGAGG \\
\hline 17 & OPM-2 & 10-mer & ACAACGCCTC \\
\hline 18 & OPM-5 & 10-mer & GGGAACGTGT \\
\hline 19 & OPM-17 & 10-mer & TCAGTCCGGG \\
\hline 20 & OPZ-18 & 10-mer & AGGGTCTGTG \\
\hline
\end{tabular}

PCR amplification was performed in a Perkin-Elmer/GeneAmp® PCR System 9700 (PE Applied Biosystems) programmed to fulfill 40 cycles after an initial denaturation cycle for $5 \mathrm{~min}$ at $94^{\circ} \mathrm{C}$. Each cycle consisted of a denaturation step at $94^{\circ} \mathrm{C}$ for $1 \mathrm{~min}$, an annealing step at $36^{\circ} \mathrm{C}$ for $1 \mathrm{~min}$, and an elongation step at $72^{\circ} \mathrm{C}$ for $1.5 \mathrm{~min}$. The primer extension segment was extended to $7 \mathrm{~min}$ at $72^{\circ} \mathrm{C}$ in the final cycle.

The amplification products were resolved by electrophoresis in a 1,5\% agarose gel containing ethidium bromide $(0.5 \mathrm{ug} / \mathrm{ml})$ in $1 \mathrm{X}$ TBE buffer at 95 volts. PCR products were visualized on UV light and photographed using a Polaroid camera. Amplified products were visually examined and the presence or absence of each size class was scored as 1 or 0 , respectively.

\section{Data Analysis}

The banding patterns generated by RAPD-PCR marker analyses were compared to determine the genetic relatedness of the. Clear and distinct amplification products were scored as ' 1 ' for presence and ' 0 ' for absence of bands. Bands of the same mobility were scored as identical.

The genetic similarity coefficient (GS) between two genotypes was estimated according to Dice coefficient Sneath and Sokal, (1973).

Dice formula: $G S i j=2 a /(2 a+b+c)$ 
Where GSij is the measure of genetic similarity between individuals $i$ and $j, \mathbf{a}$ is the number of bands shared by $i$ and $j, \mathbf{b}$ is the number of bands present in $i$ and absent in $j$, and $\mathbf{c}$ is the number of bands present in $j$ and absent in $i$.

The similarity matrix was used in the cluster analysis. The cluster analysis was employed to organize the observed data into meaningful structures to develop taxonomies. At the first step, when each accession represents its own cluster, the distances between these accessions are defined by the chosen distance measure (Dice coefficient). However, once several accessions have been linked together, the distance between two clusters is calculated as the average distance between all pairs of accessions in the two different clusters. This method is called Unweighted Pair Group Method using Arithmetic Average (UPGMA) Sneath and Sokal, (1973)

\section{Results}

Family schilbidae characterized by the anal fin base very long, not confluent with caudal, 24-90 rays; usually four pairs of barbels. The pelvic fin is occasionally absent in species of several genera. Members of this family tend to swim in open water Nelson, (2006). The objectives of this experiment were focused on detection of RAPD pattern for schlibe fishes and determination of the genetic variation among these fishes Ambak et al. (2006).

In the present work three species of family Schilbidae: Schilbe mystus, Schilbe uranoscopus and Siluranodon auritus, adopted in controlled environment in Upper Egypt, were molecule-genetically studied, using by using Randomly Amplified Polymorphism DNA (RAPD-PCR) technique. The short ten nucleotide primers generated discrete DNA amplified fragments of varying lengths and revealed RAPD variation among the species.

Twenty primers (table 1) were used in the present investigation to determine the genetic variations among three species of family Schilbidae (Schilbe mystus, Schilbe uranoscopus and Siluranodon auritus). All twenty primers amplified successfully on the genomic DNA extracted from all studied fish species. The twenty primers yielded amplification products in the three species of the family Schilbidae. The number of fragments amplified per primer varied between 7 (OPE-10) and 21 (OPG-02) (14.57 bands/ primer) and had a size range from $200 \mathrm{bp}$ (OPB - 17, OPC - 1, OPE - 6, OPM - 17 - OPA - 4 and OPM - 5) to 3000 bp (OPG-02). The DNA fragments generated by the twenty primers from the genomic DNA of the three species were separated using Agarose gel electrophoresis and illustrated in figs $(4,5,6,7,8,9$ and10). The banding patterns of these DNA fragments were analyzed by Gene profiler computer software program and summarized in tables $(2,3,4,5,6,7,8,9,10,11,12$, $13,14,15,16,17,18,19,20$ and 21). The number and positions of the bands depended on species and primer as shown in these tables.

The number of bands was variable in each species. Schilbe mystus was the species that produced number of amplified bands 174, and in Schilbe uranoscopus 193, while in Siluranodon auritus 210 bands. A total of 295 DNA bands were generated by all primers in all specimen, out of these DNA bands $97(32.88 \%)$ were conserved among all specimens, while 198 bands were polymorphic with percentage $67.12 \%$ of all the twenty tested primers produced polymorphism in all specimens ( table22). The RAPD bands profile for these species as seen in the Figures $(4,5,6,7,8,9$ and10) indicated specificity of the DNA patterns for a given species. We have found that the primers of same length but with different sequences generated different DNA patterns among fishes. The results of the (RAPD-PCR) DNA analysis were compared with those obtained from the classical methods in taxonomy using morphological and anatomical characters alone, the following are the amplification results of the three species obtained by the examined primers:

Schilbe mystus

All the primers amplified successfully on the genomic DNA from Schilbe mystus yielded distinct RAPD pattern. The twenty primers generated 174 amplified bands present in Schilbe mystus. The number of fragment amplified per primer varied from 1 fragment by the primer (OPA - 4) to 14 fragments by the primers (OPE -6 and OPM - 5) and the size of these fragments arranged from 200 to $3000 \mathrm{bp}$. The primer (OPG - 2) generated the largest size of the fragments $3000 \mathrm{bp}$., while the primers (OPB - 17, OPC - 1, OPE - 6 and OPM - 17) generated the smallest size $200 \mathrm{bp}$. of fragments.

\section{Schilbe uranoscopus}

A primary evaluation of the twenty oligonucleotides, tested on the Schilbe uranoscopus species, indicated that the primers produced amplification products ranging from approximately $200 \mathrm{bp}$. by the primers OPA - 4, OPB - 17, OPE - 6 and OPM - 5 to $1500 \mathrm{bp}$. by the primer OPA - 15 .

The twenty primers amplified (193) fragments presented in Schilbe uranoscopus species. The twenty primers used in the amplifications reactions produced various numbers of fragments for the species Schilbe uranoscopus, the largest number of fragments was 15 fragments generated by the primers OPA - 15 and OPE 6 , while the smallest number of fragments was 3 fragments generated by the primer OPF -6 . 


\section{Siluranodon auritus}

All the twenty different primers used in study, produced different band patterns. The number of amplified bands detected varied, depending on the primers and treatments. These primers amplified 210 bands presented in Siluranodon auritus. The bands ranged in size from 200 bp by primers (OPE-6 and OPM-17) to 2000 bp. by (OPE-5). The bands generated by the twenty primers, varied in number from 2 by primer OPE-10 to 17 by OPA-7.

\section{Similarity matrix UPGMAJaccard's Coefficient:}

Data of the presence / absence of DNA fragments of Schilbe mystus, Schilbe uranoscopus and Siluranodon auritus, were used to calculate the genetic similarity. Then based on the calculated genetic similarity presented in table (23) and Dendrogram as figure 11, an estimation of the relationship between the above species was concluded where the lowest genetic similarity 60.8 was observed between, Schilbe uranoscopus and Siluranodon auritus, while the highest value $\mathbf{7 3}$ was found between Schilbe mystus and Schilbe uranoscopus.

The phylogenetic relationships and genome specificity among three species of Schilbe catfishes (Schilbe mystus, Schilbe uranoscopus and Siluranodon auritus) were investigated using RAPD markers as discriminating characters for first time in Egypt.

\section{Discussion}

Here we report a study on the genetic variation of Schilbe species throughout Upper Egypt by means of random amplified polymorphic DNA (RAPD) fingerprinting. Our aim was to investigate the genetic variation within and between the three species Schilbe mystus, Schilbe uranoscopus and Siluranodon auritus). This information can improve our understanding of the relationship between the genus Schilbe and the genus Siluranodon.

All the primers which amplified successfully on the genomic DNA from the samples (Schilbe mystus, Schilbe uranoscopus and Siluranodon auritus) yielded distinct RAPD pattern. The number of fragment amplified per primer varied between (7- 21) fragments and had a size arranged from $(\mathbf{2 0 0}-\mathbf{3 0 0 0}$ bp. $)$. The results obtained in this study showed that RAPD could be used to generate useful fingerprints characteristic of fish species and for genotyping of individuals within the species. Thus, it provides an efficient and sensitive method which can be used to estimate genetic variability, relatedness, inbreeding levels, pedigree analyses, detection of economic traits and in other maker based studies in fishes Shair et al. (2011).

Random Amplified Bolymorphic DNA (RABD) was used to profile the genetic diversity of population Fouz et al. (2007). The RABD offered a quick and inexpensive molecular tool that assisted to distinguish, monitor and manage the genetic diversity of natural populations of fish raised in fish hatcheries fish Brahmane et al. (2006). RAPD analysis is useful since different number and size of fragments in different fish species can be obtained. Different fish species were given different number and size of bands (Bielawski and Pumo, (1997); Elo et al. (1997); Smith et al. (1997); Asma, (1999) and Liu Z.J. et al. (1999)).

Using RAPD fingerprinting on fish has been limited so in the current study, this technique was applied to analyze the genetic relationships among schlibe species. Using a RAPD analysis, the intrapopulation variation was detected with different primers in tilapia Bardakci and Skibinski, (1994). This technique was more sensitive than the mtDNA analysis which failed to reveal the variation within the tilapia populations (Capili, (1990) and Seyoum and Kornfield, (1992)). RAPD has been used to detect genotoxic-induced DNA damage and mutations in different organisms, including fish Atienzar and Jha (2006).

Although several amplified fragments were shared by all three Species, clearly distinguishable bands were observed only in a determined species (Schilbe mystus, Schilbe uranoscopus and Siluranodon auritus) was evident from high number of polymorphic marker. Present study indicated that least genetic distance was observed in Schilbe mystus and Schilbe uranoscopus these two species fell into a distinct cluster from other species Siluranodon auritus. This points out that these two species are genetically closer and show divergence as compared to other species of Siluranodon auritus. These two species are considered morphologically closer in contrast to the other species of Schilbe.

RAPD is one of the simplest molecular tools for genetic and systematic analyses of various organisms and has provided important applications in catfish Bartish et al. (2000). Random amplified polymorphic DNA (RAPD) analysis has been widely used in genetic diversity studies, identification of fish species, genetic differentiation in intra- or interpopulation breeding, DNA detection and so on, as it is a quick, sensitive and easy technique (Bardakci and Skibinski, (1994); Ding et al. (1998); Liu, Z.H et al. (1999); Liu, Z.J. et al. (1999) and Yoon and Kim, (2001).

It is further suggested that the use of more numbers of random primers from different operon series in more numbers of samples might be helpful to achieve more reliable results in the genetic studies Chandra $\boldsymbol{e t}$ al. 
(2010). The RAPD method was successfully used to detect the variation between the different species of fish Bardakci and Skibinski, (1994).

In conclusion, the RAPD method was successfully used to detect the variation between the different species of fishes. The results obtained in this study showed that RAPD could be used to generate useful fingerprints characteristic of fish species and for genotyping of individuals within the species. The results indicated that each species has different molecular genetic characteristics. The cluster analysis clearly differentiated Schilbe mystus and Schilbe uranoscopus from Siluranodon auritus. The molecular genetic taxonomic relationship among three species of Serranidae fishes (Schilbe mystus, Schilbe uranoscopus and Siluranodon auritus) were investigated using RAPD markers for first time in Egypt.

\section{References}

[1]. Ali, B. A. (2003): Genetics similarity among four breeds of sheep in Egypt detected by random amplified polymorphic DNA markers, Afr. J. Biotechnol., 2 (7): $194-197$.

[2]. Ambak, M. A.; Bolong, A. A.; Ismail, P. and MinhTam, B. (2006): Genetic variation of Snakehead fish (Channa striata) populations using Random Amplified Polymorphic DNA. Biotechnology, 5: 104-110.

[3]. Asma, A. N. (1999): Genetic variation between and within three varieties and domesticated Tiger barb (Puntius tetrazona) using RADP markers. M.Sc Thesis, Univ. Putra Malaysia.

[4]. Atienzar, F. A. and Jha, A. N. (2006): The random amplified polymorphic DNA (RAPD) assay and related techniques applied to genotoxicity and carcinogenesis studies: A critical review. Mutat. Res., 613(2-3):76-102.

[5]. Bardakci, F. (2001): Random Amplified Polymorphic DNA (RAPD) Markers. Turk. J. Biol., 25: 185-196.

[6]. Bardacki, F. and Skibinski, D. O. F. (1994): Applications of the RAPD technique in tilapia fish: species and subspecies identification. Heredity 73: 117-123.

[7]. Bartish, I. V. ; Garkava, L. P. ; Rumpunen, K. and Nybom, H. ( 2000): Phylogenetic relationships and differentiation among and within populations of Chaenomeles Lindl. (Rosaceae) estimated with RAPDs and isozymes. Theor. Appl. Genet., 101: 554 561.

[8]. Bielawski, J. P. and Pumo, D. E. (1997) : Random amplified polymorphic DNA (RAPD) analysis of Atlantic coast stripped bass. Heredity, 73: 32-40.

[9]. Bishai, H. M. and khalil, M. T.. Y. B. (1997): Aquatic ecologist, Ain _ Shams university publication of National biodiversity. Unit, No. 9.

[10]. Brahmane, M. P., Das, M. K.; Sinha, M. R.; Sugunan, V. V. and Mukherjee, A. (2006): Use of RAPD fingerprinting for delineating populations of hilsa shad Tenualosa ilisha (Hamilton, 1822). Genet. Mol. Res., 5 (4): 643-652.

[11]. Capili, J. B. (1990): Isozyme and Mitochondrial DNA Restriction Endonuclease Analysis of Three Strains of Oreochromis nilitocus Dissertation, University of Wales.

[12]. Chandra, G.; Saxen, A. and Barat, A. (2010): Genetic diversity of two riverine populations of Eutropiichthys vacha (Hamilton, 1822) using RAPD markers and implications for its conservation. Journal of Cell and Molecular Biology, 8(2): 77-85.

[13]. Ding, S.X.; Wang, J.; Quan, C.G. and Su, Y.Q. (1998): Gentic diversity in population of cultured Nibea miichthioides. Bulletin of Science 43(21): 2294-2299 (in Chinese).

[14]. Elo, K.; Ivanoff, S.; Vuorinen, J. A. and Piironen, J. (1997): Inheretance of RAPD markers and detection of interspecific hybridization with brown trout and Atlantic salmon. Aquaculture, 152: 55-65.

[15]. Erlich, H. A. ( 1989): PCR Technology Principles and Applications for DNA amplification. Stockton Press, New York.

[16]. Fouz, B.; Roig, F. J. and Amaro, C. (2007): Phenotypic and genotypic characterization of a new fish-virulent Vibrio vulnificus serovar that lacks potential to infect humans. Microbiology, 153: 1926-1934.

[17]. Hallerman, E., Brown, B. and Epifanio, J. (2003): An overview of classical molecular genetics. E. M. Hallerman (Ed.), Population genetics: principles and applications for fisheries scientists. American Fisheries Society, Bethesda, Maryland, 1-20.

[18]. Le Comber, S. C. and Smith, C. (2004): Polyploidy in fishes: patterns and processes. The Linnean Society of London, Biological Journal of the Linnean Society, 82: 431-442.

[19]. Lee, Y. C.; Yang, V. C. and Wang, T. S. (2007): Use of RAPD to detect sodium arsenite-induced DNA damage in human lymphoblastoid cells, Toxicology, 239: 108-115.

[20]. Liu, Z.H.; Shi, T.; Liu, X.Z.; Chen, C. and Kong, J. (1999): Identification of three populations (Chinese Fugu rubripes, Japanese Fugu rubripes and Fugu pseudommus) using RAPD markers. Transactions of Oceanology and Limnology 4: 38-41 (in Chinese).

[21]. Liu, Z.J.; Li, P.; Argue, B.J. and Dunham, R.A. (1999): Random amplified polymorphic DNA markers: usefulness for gene mapping and analysis of genetic variation of catfish. Aquaculture174: 59-68.

[22]. Mekkawy, I. A. A. and Hassan, A. A. (2011): Some Reproductive Parameters of Synodontis schall (Bloch and Schneider, 1801) from the River Nile, Egypt. J. Fish. Aquat. Sci, 6 (4): 456-471

[23]. Nelson, J. S. ( 2006): Fishes of the World. 4th. edn, John Wiley and Sons, Inc. 1-601 pp.

[24]. Okumus, I. and Ciftci, Y. (2003): Fish Population Genetics and Molecular Markers: II- Molecular Markers and Their Applications in Fisheries and Aquaculture, Turk. J. Fish. Aquat. Sci., 3: 51-79.

[25]. Seyoum, S. and Kornfield, I. (1992): Identification of the subspecies of Oreochromis niloticus (Pisces:Cichlidae) using restriction endonuclease analysis of mitochondrial DNA. Aquaculture 102, 29-42.

[26]. Shair, O. H. M.; Al-Ssum, R. M. and Bahkali, A. H. (2011): Genetic Variation Investigation of Tilapia Grown under Saudi Arabian Controlled Environment. Am. J. Biochem. Mol. Biol., 1 (1): 89-94.

[27]. Smith, P. J.; Benson, P. G. and McVeagh, S. M. (1997): Comparison of three genetic

[28]. methods used for stock discrimination of orange roughy, Hoplostethus atlanticus: Allozymes,

[29]. mitochondrial DNA and Random Amplified Polymorphic DNA. Fish. Bull., 95: 800-811.

[30]. Sneath, P. H. A. and Sokal, R. R. (1973): Numerical taxonomy - The principles and

[31]. practice of numerical classification. W. H. Freeman, San Francisco. 573p p.

[32]. Weising, K.; Nybom, H.; Wolff, K. and Meyer, W. (1995): DNA Fingerprinting in Plants and Fungi. CRC Press, Boca Raton, FL, USA.

[33]. Welsh, J. and McClelland, M. (1990): Fingerprint genomes using PCR with arbitrary primers. Nucleic Acids Res., 18(24): 7213-7218. 
[34]. Williams, J. G. K.; Kubelik, A. R. K.; Livak, K. J.; Rafalski, J.A. and Tingey, S. V. (1990): DNA polymorphisms amplified by arbitrary primers are useful as genetic markers. Nucleic Acids Res., 18(22): 6531-6535.

[35]. Yoon, J. M. and Kim, G. W. (2001): Randomly amplified polymorphic DNA-polymerase chain reaction analysis of two different populations of cultured Korean catfish Silurus asotus. J. Biosci., 26(5): 641-647.

[36]. Zhivotovsky, L. A. (1999): Estimating population structure in diploids with multilocus dominant DNA markers. Mol. Ecol., 8(6): 907-913.

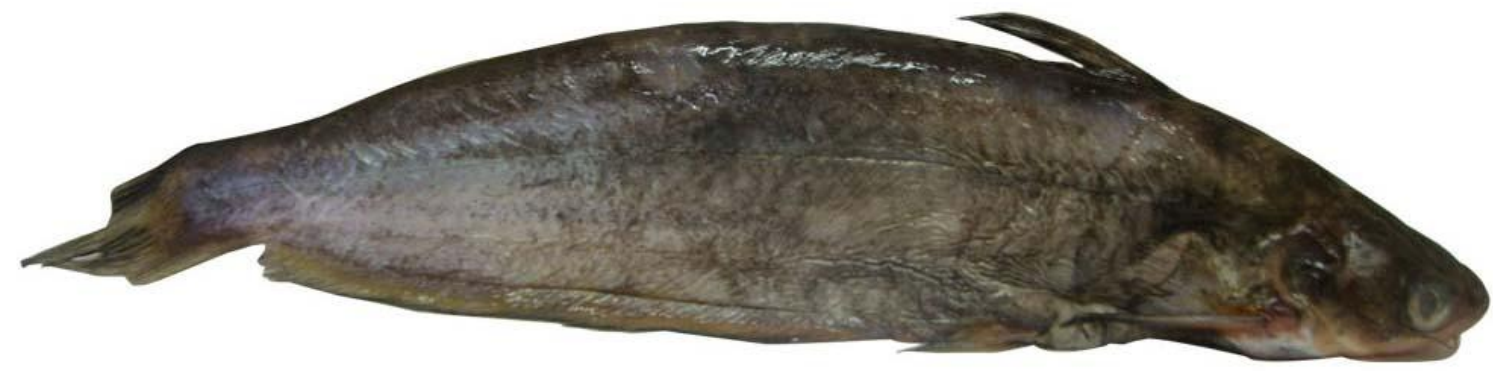

Fig (1): The external features of Schilbe mystus.

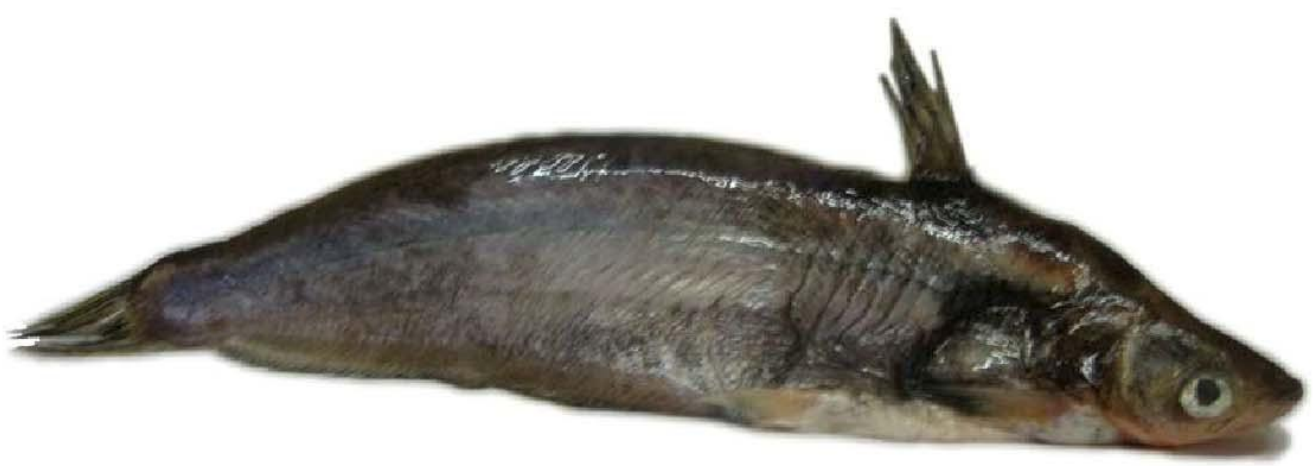

Fig (2): The external features of Schilbe uranoscopus.

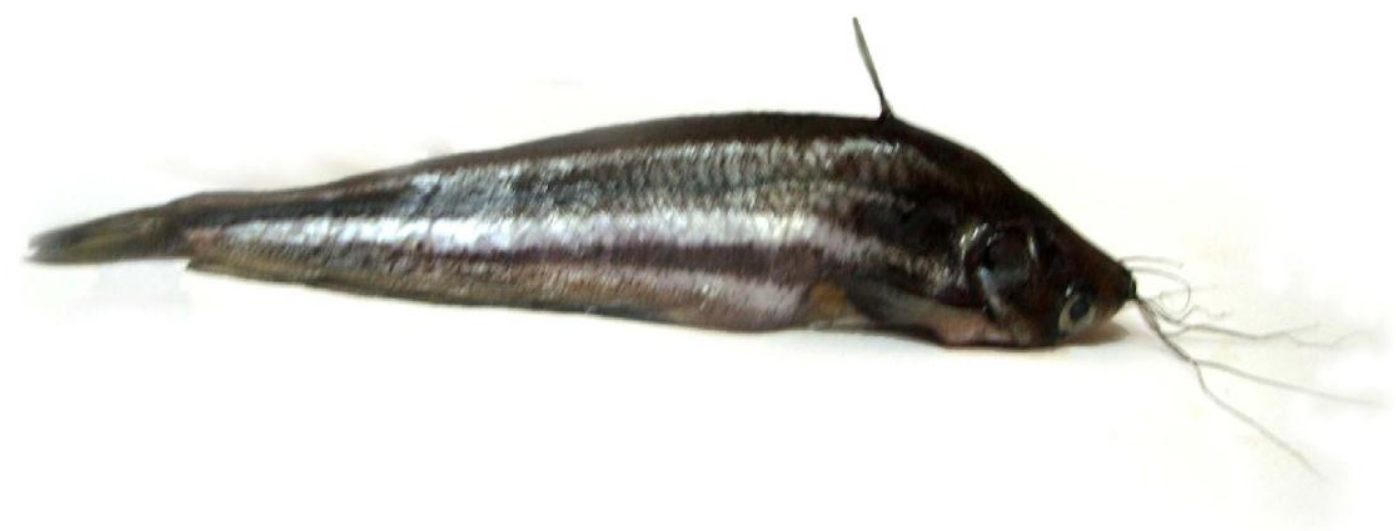

Fig (3): The external features of Siluranodon auritus. 


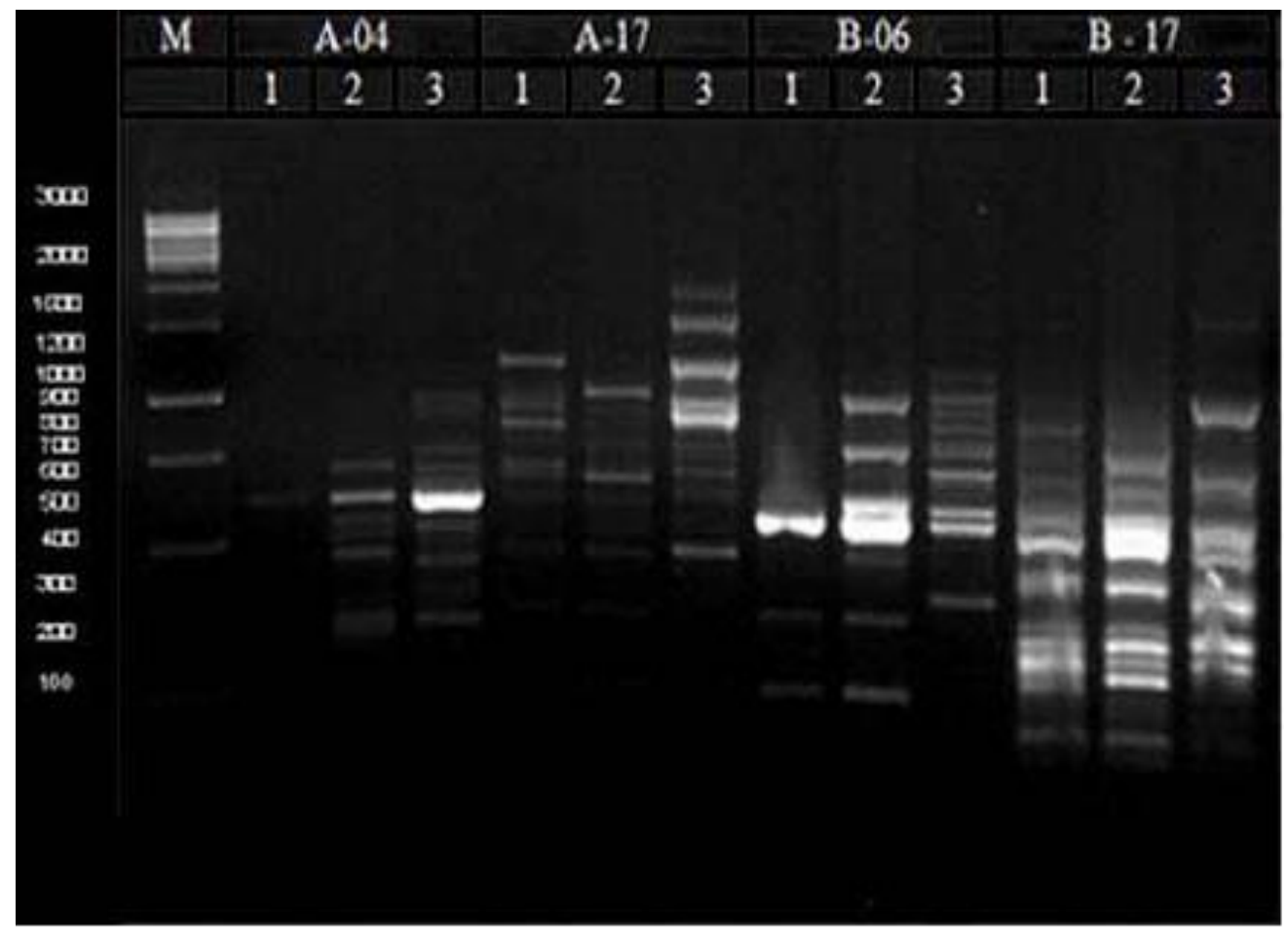

Fig (4): Agarose-gel electrophoresis products generated with primers OPA-4, OPA-17, OPB-6 and OPB-17. (1- Schilbe mystus, 2- Schilbe uranoscopus 3-Siluranodon auritus)

\begin{tabular}{|c|c|c|c|c|}
\hline & & \multicolumn{3}{|c|}{ OPA - 04 } \\
\hline No. & M & 1 & 2 & 3 \\
\hline 1 & 1000 & 0 & 1 & 1 \\
\hline 2 & 950 & 0 & 0 & 1 \\
\hline 3 & 820 & 0 & 0 & 1 \\
\hline 4 & 750 & 0 & 1 & 1 \\
\hline 5 & 680 & 0 & 0 & 1 \\
\hline 6 & 600 & 1 & 1 & 1 \\
\hline 7 & 570 & 0 & 1 & 0 \\
\hline 8 & 530 & 0 & 0 & 1 \\
\hline 9 & 500 & 0 & 1 & 0 \\
\hline 10 & 480 & 0 & 1 & 1 \\
\hline 11 & 370 & 0 & 0 & 1 \\
\hline 12 & 300 & 0 & 1 & 1 \\
\hline 13 & 220 & 0 & 1 & 1 \\
\hline 14 & 200 & 0 & 1 & 0 \\
\hline
\end{tabular}

Table (2): Survey of RAPD Markers using primer (OPA-4). (1- Schilbe mystus, 2- Schilbe uranoscopus 3Siluranodon auritus), where (1) means present and (0) means absence.

\begin{tabular}{|c|c|c|c|c|}
\hline & & \multicolumn{3}{|c|}{ OPA - 17 } \\
\hline \multirow{2}{*}{ No. } & & & & \\
& M & 1 & 2 & 3 \\
\hline 1 & 1800 & 0 & 0 & 1 \\
\hline 2 & 1500 & 0 & 0 & 1 \\
\hline 3 & 1300 & 1 & 0 & 1 \\
\hline 4 & 1250 & 0 & 1 & 1 \\
\hline 5 & 1000 & 1 & 1 & 1 \\
\hline 6 & 920 & 1 & 1 & 1 \\
\hline 7 & 850 & 0 & 1 & 0 \\
\hline 8 & 750 & 1 & 0 & 1 \\
\hline 9 & 700 & 1 & 1 & 0 \\
\hline 10 & 650 & 1 & 1 & 1 \\
\hline
\end{tabular}


Molecular Genetic Variations and Phylogenetic Relationship Using Random Amplified polymorphic

\begin{tabular}{|l|l|l|l|l|}
11 & 580 & 0 & 1 & 0 \\
\hline 12 & 500 & 1 & 1 & 1 \\
\hline 13 & 480 & 0 & 0 & 1 \\
\hline 14 & 400 & 1 & 1 & 0 \\
\hline 15 & 270 & 0 & 1 & 1 \\
\hline
\end{tabular}

Table (3): Survey of RAPD Markers using primer (OPA-17).

\begin{tabular}{|c|c|c|c|c|}
\hline & & \multicolumn{3}{|c|}{ OPB -06} \\
\hline No. & M & $\mathbf{1}$ & $\mathbf{2}$ & $\mathbf{3}$ \\
\hline $\mathbf{1}$ & $\mathbf{1 1 0 0}$ & $\mathbf{0}$ & $\mathbf{0}$ & $\mathbf{1}$ \\
\hline $\mathbf{2}$ & $\mathbf{1 0 0 0}$ & $\mathbf{0}$ & $\mathbf{1}$ & $\mathbf{1}$ \\
\hline $\mathbf{3}$ & $\mathbf{9 0 0}$ & $\mathbf{0}$ & $\mathbf{0}$ & $\mathbf{1}$ \\
\hline $\mathbf{4}$ & $\mathbf{8 3 0}$ & $\mathbf{0}$ & $\mathbf{0}$ & $\mathbf{1}$ \\
\hline $\mathbf{5}$ & $\mathbf{7 8 0}$ & $\mathbf{0}$ & $\mathbf{0}$ & $\mathbf{1}$ \\
\hline $\mathbf{6}$ & $\mathbf{7 5 0}$ & $\mathbf{0}$ & $\mathbf{1}$ & $\mathbf{1}$ \\
\hline $\mathbf{7}$ & $\mathbf{7 0 0}$ & $\mathbf{0}$ & $\mathbf{0}$ & $\mathbf{1}$ \\
\hline $\mathbf{8}$ & $\mathbf{6 5 0}$ & $\mathbf{1}$ & $\mathbf{1}$ & $\mathbf{1}$ \\
\hline $\mathbf{9}$ & $\mathbf{6 0 0}$ & $\mathbf{1}$ & $\mathbf{1}$ & $\mathbf{1}$ \\
\hline $\mathbf{1 0}$ & $\mathbf{5 0 0}$ & $\mathbf{0}$ & $\mathbf{1}$ & $\mathbf{0}$ \\
\hline $\mathbf{1 1}$ & $\mathbf{4 0 0}$ & $\mathbf{0}$ & $\mathbf{0}$ & $\mathbf{1}$ \\
\hline $\mathbf{1 2}$ & $\mathbf{3 8 0}$ & $\mathbf{1}$ & $\mathbf{1}$ & $\mathbf{0}$ \\
\hline $\mathbf{1 3}$ & $\mathbf{2 6 0}$ & $\mathbf{1}$ & $\mathbf{1}$ & $\mathbf{0}$ \\
\hline
\end{tabular}

\begin{tabular}{|c|c|c|c|c|}
\hline & & \multicolumn{3}{|c|}{ OP: B17 } \\
\hline No. & M & 1 & 2 & 3 \\
\hline 1 & 1500 & 0 & 0 & 1 \\
\hline 2 & 1000 & 1 & 1 & 1 \\
\hline 3 & 850 & 1 & 1 & 0 \\
\hline 4 & 750 & 0 & 1 & 0 \\
\hline 5 & 680 & 1 & 1 & 1 \\
\hline 6 & 600 & 1 & 1 & 1 \\
\hline 7 & 550 & 1 & 1 & 1 \\
\hline 8 & 450 & 1 & 1 & 1 \\
\hline 9 & 420 & 1 & 0 & 1 \\
\hline 10 & 400 & 0 & 0 & 1 \\
\hline 11 & 350 & 1 & 1 & 0 \\
\hline 12 & 300 & 1 & 1 & 1 \\
\hline 13 & 270 & 1 & 1 & 1 \\
\hline 14 & 230 & 1 & 1 & 1 \\
\hline 15 & 200 & 1 & 1 & 0 \\
\hline
\end{tabular}

Table (4): Survey of RAPD Markers using primer (OPB-6).

Table (5): Survey of RAPD Markers using primer (OPB-17).

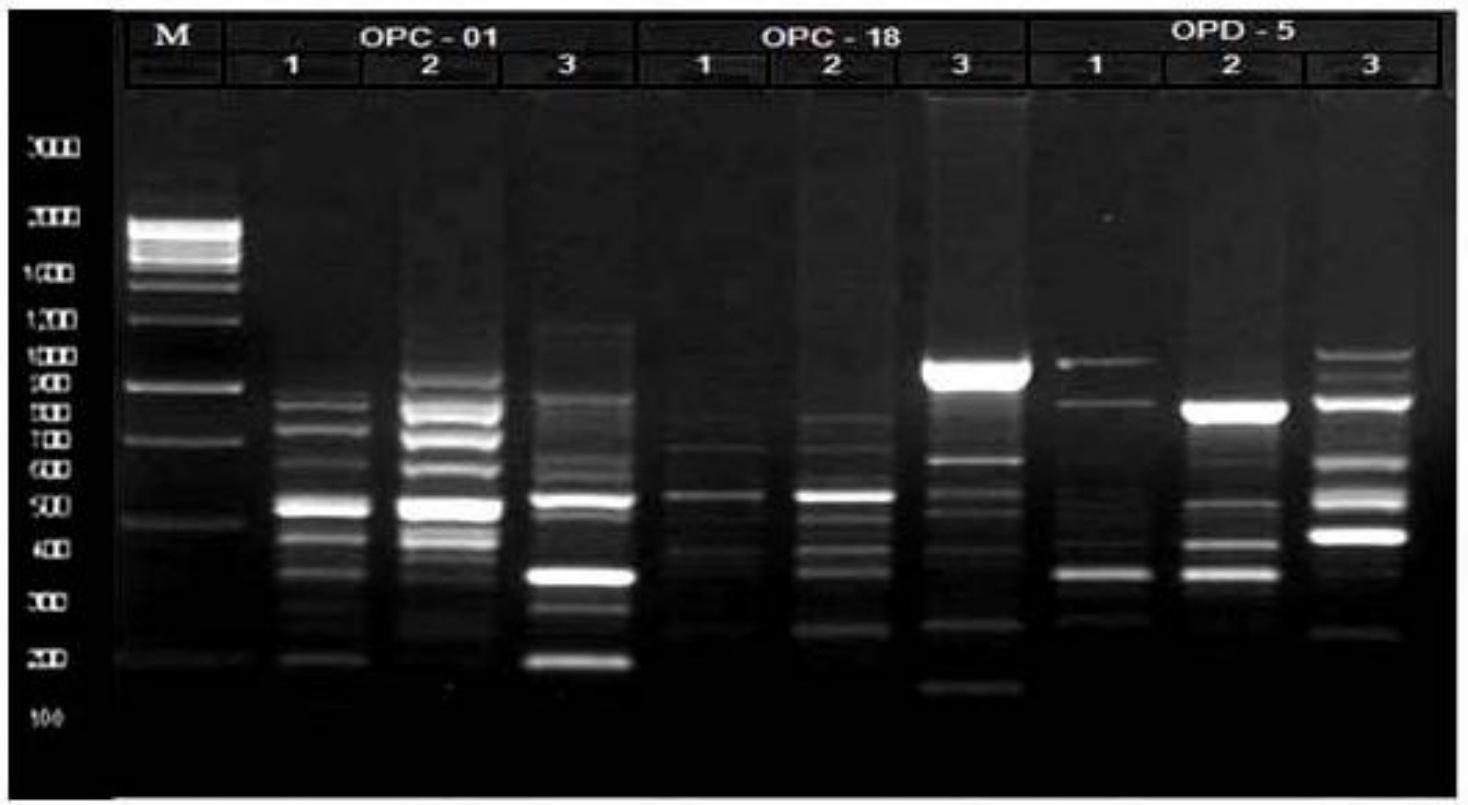

Fig (5): Agarose-gel electrophoresis products generated with primers OPC-1, OPC-18 and OPD-5. 


\begin{tabular}{|c|c|c|c|c|}
\hline & & \multicolumn{3}{|c|}{ OPC - 01 } \\
\hline No. & M & $\mathbf{1}$ & $\mathbf{2}$ & $\mathbf{3}$ \\
\hline $\mathbf{1}$ & $\mathbf{1 5 0 0}$ & $\mathbf{0}$ & $\mathbf{0}$ & $\mathbf{1}$ \\
\hline $\mathbf{2}$ & $\mathbf{1 2 0 0}$ & $\mathbf{0}$ & $\mathbf{1}$ & $\mathbf{0}$ \\
\hline $\mathbf{3}$ & $\mathbf{1 0 0 0}$ & $\mathbf{1}$ & $\mathbf{1}$ & $\mathbf{1}$ \\
\hline $\mathbf{4}$ & $\mathbf{9 0 0}$ & $\mathbf{1}$ & $\mathbf{1}$ & $\mathbf{0}$ \\
\hline $\mathbf{5}$ & $\mathbf{8 0 0}$ & $\mathbf{1}$ & $\mathbf{1}$ & $\mathbf{0}$ \\
\hline $\mathbf{6}$ & $\mathbf{7 5 0}$ & $\mathbf{0}$ & $\mathbf{0}$ & $\mathbf{1}$ \\
\hline $\mathbf{7}$ & $\mathbf{7 0 0}$ & $\mathbf{1}$ & $\mathbf{1}$ & $\mathbf{1}$ \\
\hline $\mathbf{8}$ & $\mathbf{6 0 0}$ & $\mathbf{1}$ & $\mathbf{1}$ & $\mathbf{1}$ \\
\hline $\mathbf{9}$ & $\mathbf{5 5 0}$ & $\mathbf{1}$ & $\mathbf{1}$ & $\mathbf{1}$ \\
\hline $\mathbf{1 0}$ & $\mathbf{5 0 0}$ & $\mathbf{0}$ & $\mathbf{1}$ & $\mathbf{0}$ \\
\hline 11 & $\mathbf{4 8 0}$ & $\mathbf{1}$ & $\mathbf{1}$ & $\mathbf{0}$ \\
\hline 12 & $\mathbf{4 5 0}$ & $\mathbf{1}$ & $\mathbf{1}$ & $\mathbf{0}$ \\
\hline 13 & $\mathbf{4 0 0}$ & $\mathbf{1}$ & $\mathbf{1}$ & $\mathbf{1}$ \\
\hline 14 & $\mathbf{3 5 0}$ & $\mathbf{1}$ & $\mathbf{0}$ & $\mathbf{1}$ \\
\hline 15 & $\mathbf{3 0 0}$ & $\mathbf{1}$ & $\mathbf{1}$ & $\mathbf{0}$ \\
\hline 16 & $\mathbf{2 5 0}$ & $\mathbf{1}$ & $\mathbf{1}$ & $\mathbf{1}$ \\
\hline 17 & $\mathbf{2 0 0}$ & $\mathbf{1}$ & $\mathbf{0}$ & $\mathbf{0}$ \\
\hline
\end{tabular}

Table (6): Survey of RAPD Markers using primer (OPC-1).

\begin{tabular}{|c|c|c|c|c|}
\hline & & \multicolumn{3}{|c|}{ OP: C18 } \\
\hline No. & M & 1 & 2 & 3 \\
\hline 1 & 1050 & 0 & 0 & 1 \\
\hline 2 & 900 & 1 & 1 & 1 \\
\hline 3 & 750 & 1 & 1 & 0 \\
\hline 4 & 700 & 0 & 0 & 1 \\
\hline 5 & 650 & 0 & 1 & 0 \\
\hline 6 & 600 & 1 & 1 & 1 \\
\hline 7 & 500 & 1 & 1 & 0 \\
\hline $\mathbf{8}$ & 450 & 1 & 1 & 1 \\
\hline 9 & 400 & 1 & 1 & 0 \\
\hline 10 & 300 & 1 & 1 & 1 \\
\hline 11 & 220 & 0 & 0 & 1 \\
\hline
\end{tabular}

Table (7): Survey of RAPD Markers using primer (OPC-18).

\begin{tabular}{|c|c|c|c|c|}
\hline & & \multicolumn{3}{|c|}{ OPD - 05 } \\
\hline No. & M & $\mathbf{1}$ & $\mathbf{2}$ & $\mathbf{3}$ \\
\hline $\mathbf{1}$ & $\mathbf{1 2 0 0}$ & $\mathbf{1}$ & $\mathbf{0}$ & $\mathbf{1}$ \\
\hline $\mathbf{2}$ & $\mathbf{1 1 0 0}$ & $\mathbf{0}$ & $\mathbf{0}$ & $\mathbf{1}$ \\
\hline $\mathbf{3}$ & $\mathbf{9 5 0}$ & $\mathbf{1}$ & $\mathbf{1}$ & $\mathbf{1}$ \\
\hline $\mathbf{4}$ & $\mathbf{7 0 0}$ & $\mathbf{1}$ & $\mathbf{1}$ & $\mathbf{1}$ \\
\hline $\mathbf{5}$ & $\mathbf{6 0 0}$ & $\mathbf{1}$ & $\mathbf{0}$ & $\mathbf{1}$ \\
\hline $\mathbf{6}$ & $\mathbf{5 5 0}$ & $\mathbf{1}$ & $\mathbf{1}$ & $\mathbf{1}$ \\
\hline 7 & $\mathbf{5 0 0}$ & $\mathbf{1}$ & $\mathbf{1}$ & $\mathbf{0}$ \\
\hline $\mathbf{8}$ & $\mathbf{4 2 0}$ & $\mathbf{1}$ & $\mathbf{1}$ & $\mathbf{1}$ \\
\hline $\mathbf{9}$ & $\mathbf{3 8 0}$ & $\mathbf{1}$ & $\mathbf{1}$ & $\mathbf{1}$ \\
\hline $\mathbf{1 0}$ & $\mathbf{3 5 0}$ & $\mathbf{1}$ & $\mathbf{1}$ & $\mathbf{0}$ \\
\hline $\mathbf{1 1}$ & $\mathbf{3 0 0}$ & $\mathbf{1}$ & $\mathbf{0}$ & $\mathbf{1}$ \\
\hline
\end{tabular}

Table (8): Survey of RAPD Markers using primer (OPD-5). 


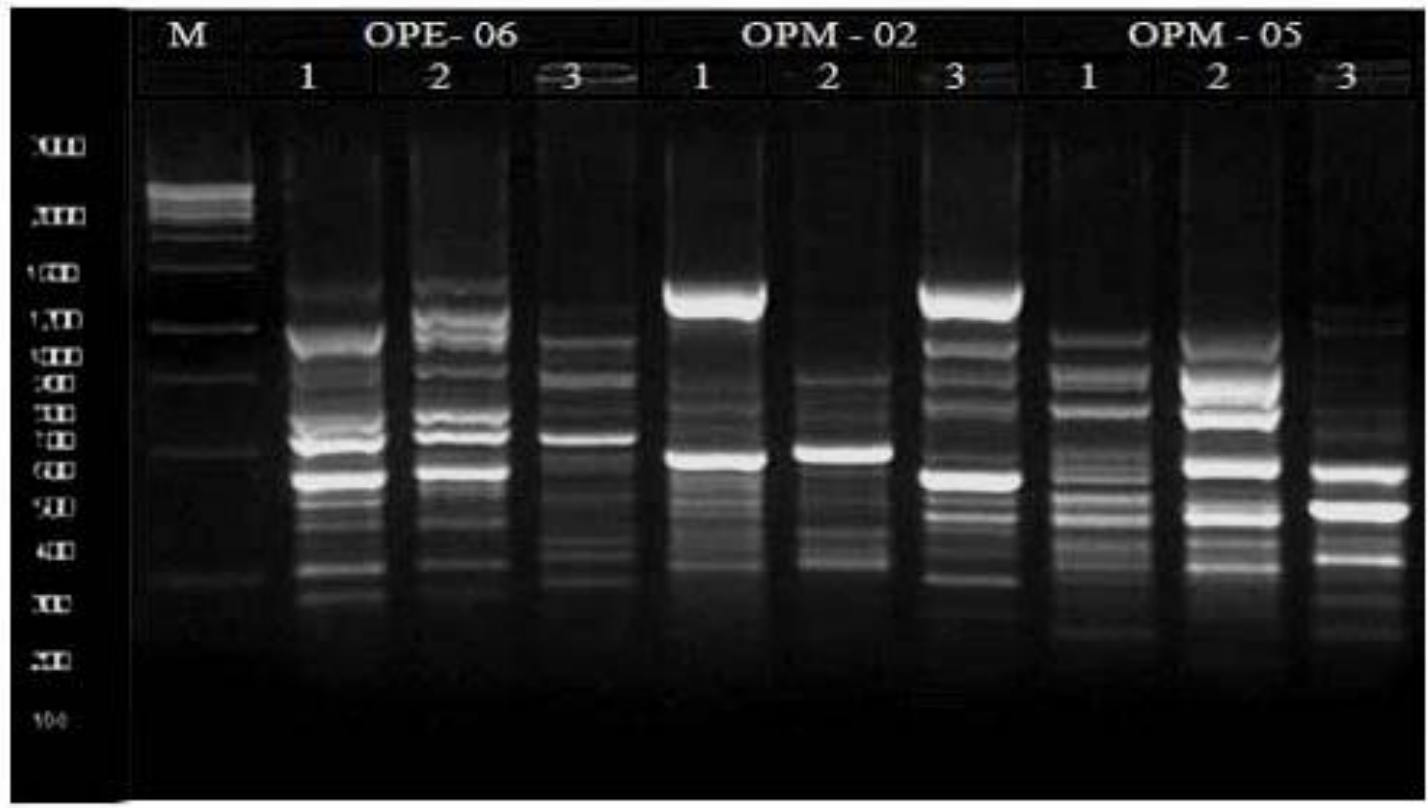

Fig (6): Agarose-gel electrophoresis products generated with primers OPE-6, OPM-2 and OPM-5.

\begin{tabular}{|c|c|c|c|c|}
\hline & & \multicolumn{3}{|c|}{ OP:E06 } \\
\hline No. & $\mathbf{M}$ & $\mathbf{1}$ & $\mathbf{2}$ & $\mathbf{3}$ \\
\hline $\mathbf{1}$ & $\mathbf{1 3 0 0}$ & $\mathbf{1}$ & $\mathbf{1}$ & $\mathbf{0}$ \\
\hline $\mathbf{2}$ & $\mathbf{1 1 0 0}$ & $\mathbf{0}$ & $\mathbf{0}$ & $\mathbf{1}$ \\
\hline $\mathbf{3}$ & $\mathbf{1 0 0 0}$ & $\mathbf{0}$ & $\mathbf{1}$ & $\mathbf{0}$ \\
\hline $\mathbf{4}$ & 900 & $\mathbf{1}$ & $\mathbf{1}$ & $\mathbf{1}$ \\
\hline $\mathbf{5}$ & $\mathbf{8 5 0}$ & $\mathbf{1}$ & $\mathbf{1}$ & $\mathbf{0}$ \\
\hline $\mathbf{6}$ & $\mathbf{7 5 0}$ & $\mathbf{1}$ & $\mathbf{1}$ & $\mathbf{1}$ \\
\hline 7 & 700 & $\mathbf{1}$ & $\mathbf{0}$ & $\mathbf{1}$ \\
\hline $\mathbf{8}$ & $\mathbf{6 5 0}$ & $\mathbf{1}$ & $\mathbf{1}$ & $\mathbf{0}$ \\
\hline $\mathbf{9}$ & $\mathbf{5 8 0}$ & $\mathbf{1}$ & $\mathbf{1}$ & $\mathbf{1}$ \\
\hline 10 & $\mathbf{5 0 0}$ & $\mathbf{1}$ & $\mathbf{1}$ & $\mathbf{1}$ \\
\hline 11 & 470 & $\mathbf{1}$ & $\mathbf{1}$ & $\mathbf{1}$ \\
\hline 12 & 450 & $\mathbf{1}$ & $\mathbf{1}$ & $\mathbf{0}$ \\
\hline 13 & 400 & $\mathbf{0}$ & $\mathbf{1}$ & $\mathbf{0}$ \\
\hline 14 & $\mathbf{3 8 0}$ & $\mathbf{1}$ & $\mathbf{1}$ & $\mathbf{1}$ \\
\hline 15 & $\mathbf{3 5 0}$ & $\mathbf{1}$ & $\mathbf{1}$ & $\mathbf{1}$ \\
\hline 16 & $\mathbf{3 0 0}$ & $\mathbf{0}$ & $\mathbf{0}$ & $\mathbf{1}$ \\
\hline 17 & $\mathbf{2 5 0}$ & $\mathbf{1}$ & $\mathbf{1}$ & $\mathbf{1}$ \\
\hline 18 & $\mathbf{2 0 0}$ & $\mathbf{1}$ & $\mathbf{1}$ & $\mathbf{1}$ \\
\hline & & & & \\
\hline
\end{tabular}

\begin{tabular}{|c|c|c|c|c|}
\hline & & \multicolumn{4}{|c|}{ OPM - 02 } \\
\hline No. & M & $\mathbf{1}$ & $\mathbf{2}$ & $\mathbf{3}$ \\
\hline $\mathbf{1}$ & $\mathbf{1 2 0 0}$ & $\mathbf{1}$ & $\mathbf{0}$ & $\mathbf{1}$ \\
\hline $\mathbf{2}$ & $\mathbf{9 0 0}$ & $\mathbf{0}$ & $\mathbf{0}$ & $\mathbf{1}$ \\
\hline $\mathbf{3}$ & $\mathbf{8 0 0}$ & $\mathbf{1}$ & $\mathbf{1}$ & $\mathbf{1}$ \\
\hline $\mathbf{4}$ & $\mathbf{7 5 0}$ & $\mathbf{0}$ & $\mathbf{1}$ & $\mathbf{0}$ \\
\hline $\mathbf{5}$ & $\mathbf{7 0 0}$ & $\mathbf{1}$ & $\mathbf{0}$ & $\mathbf{1}$ \\
\hline $\mathbf{6}$ & $\mathbf{6 0 0}$ & $\mathbf{0}$ & $\mathbf{1}$ & $\mathbf{0}$ \\
\hline $\mathbf{7}$ & $\mathbf{5 8 0}$ & $\mathbf{1}$ & $\mathbf{0}$ & $\mathbf{1}$ \\
\hline $\mathbf{8}$ & $\mathbf{5 5 0}$ & $\mathbf{1}$ & $\mathbf{1}$ & $\mathbf{1}$ \\
\hline $\mathbf{9}$ & $\mathbf{5 0 0}$ & $\mathbf{0}$ & $\mathbf{0}$ & $\mathbf{1}$ \\
\hline 10 & 450 & $\mathbf{1}$ & $\mathbf{1}$ & $\mathbf{1}$ \\
\hline 11 & 400 & $\mathbf{1}$ & $\mathbf{0}$ & $\mathbf{1}$ \\
\hline 12 & $\mathbf{3 7 0}$ & $\mathbf{0}$ & $\mathbf{0}$ & $\mathbf{1}$ \\
\hline 13 & $\mathbf{3 0 0}$ & $\mathbf{1}$ & $\mathbf{1}$ & $\mathbf{1}$ \\
\hline 14 & $\mathbf{2 7 0}$ & $\mathbf{0}$ & $\mathbf{1}$ & $\mathbf{1}$ \\
\hline 15 & $\mathbf{2 5 0}$ & $\mathbf{1}$ & $\mathbf{1}$ & $\mathbf{0}$ \\
\hline 16 & $\mathbf{2 3 0}$ & $\mathbf{0}$ & $\mathbf{0}$ & $\mathbf{1}$ \\
\hline
\end{tabular}




\begin{tabular}{|c|c|c|c|c|}
\hline \multirow[b]{2}{*}{ No. } & & \multicolumn{3}{|c|}{ OPM - 05} \\
\hline & M & 1 & 2 & 3 \\
\hline 1 & 1150 & $\mathbf{0}$ & $\mathbf{0}$ & 1 \\
\hline 2 & 1000 & $\mathbf{0}$ & 0 & 1 \\
\hline 3 & 900 & 1 & 1 & 0 \\
\hline 4 & 780 & 1 & $\mathbf{0}$ & $\mathbf{0}$ \\
\hline 5 & 750 & 1 & 1 & 0 \\
\hline 6 & 720 & $\mathbf{0}$ & 1 & $\mathbf{0}$ \\
\hline 7 & 700 & 1 & 1 & 1 \\
\hline 8 & 600 & $\mathbf{0}$ & $\mathbf{0}$ & 1 \\
\hline 9 & 550 & 1 & 0 & $\mathbf{0}$ \\
\hline 10 & 500 & 1 & 1 & 1 \\
\hline 11 & 470 & 1 & 0 & $\mathbf{0}$ \\
\hline 12 & 450 & $\mathbf{0}$ & 1 & $\mathbf{0}$ \\
\hline 13 & 430 & 1 & $\mathbf{0}$ & $\mathbf{0}$ \\
\hline 14 & 420 & 1 & 1 & 1 \\
\hline 15 & 400 & 1 & 1 & $\mathbf{0}$ \\
\hline 16 & 300 & 1 & 1 & 1 \\
\hline 17 & 260 & 1 & 1 & 1 \\
\hline 18 & 240 & 1 & 1 & 1 \\
\hline 19 & 220 & 1 & $\mathbf{0}$ & 1 \\
\hline 20 & 200 & $\mathbf{0}$ & 1 & $\mathbf{0}$ \\
\hline
\end{tabular}

Table (11): Survey of RAPD Markers using primer (OPM-5).

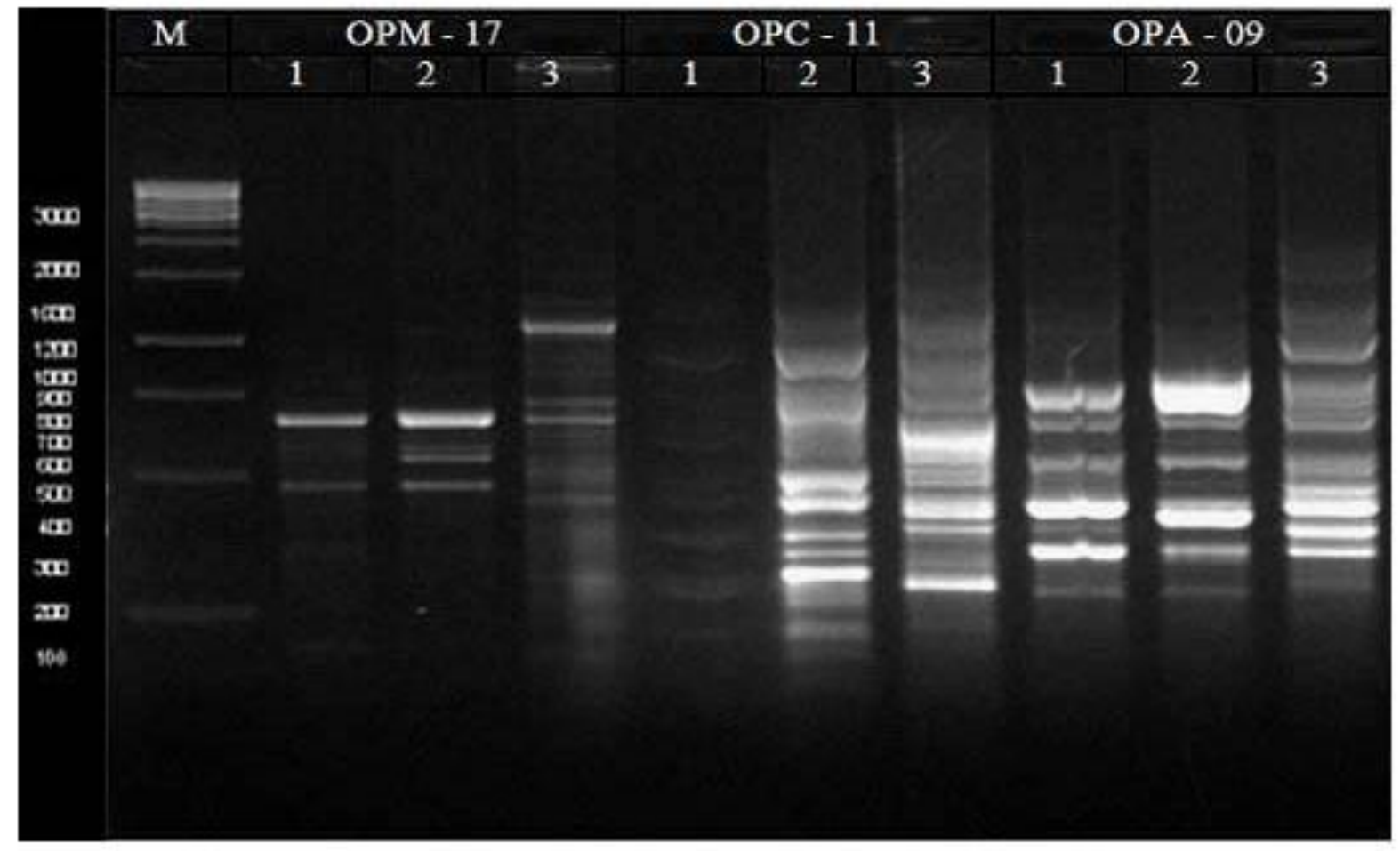

Fig (7): Agarose-gel electrophoresis products generated with primers OPM-17, OPC-11 and OPA-9. 


\begin{tabular}{|c|c|c|c|c|}
\hline & & \multicolumn{3}{|c|}{ OP:M17 } \\
\hline No. & & \multicolumn{3}{|c|}{} \\
& M & 1 & 2 & 3 \\
\hline 1 & $\mathbf{1 2 0 0}$ & $\mathbf{0}$ & $\mathbf{0}$ & $\mathbf{1}$ \\
\hline $\mathbf{2}$ & $\mathbf{1 0 0 0}$ & $\mathbf{0}$ & $\mathbf{1}$ & $\mathbf{1}$ \\
\hline $\mathbf{3}$ & $\mathbf{8 0 0}$ & $\mathbf{1}$ & $\mathbf{1}$ & $\mathbf{1}$ \\
\hline $\mathbf{4}$ & $\mathbf{7 5 0}$ & $\mathbf{0}$ & $\mathbf{0}$ & $\mathbf{1}$ \\
\hline $\mathbf{5}$ & $\mathbf{7 0 0}$ & $\mathbf{1}$ & $\mathbf{1}$ & $\mathbf{1}$ \\
\hline $\mathbf{6}$ & $\mathbf{6 5 0}$ & $\mathbf{0}$ & $\mathbf{0}$ & $\mathbf{1}$ \\
\hline $\mathbf{7}$ & $\mathbf{6 2 0}$ & $\mathbf{1}$ & $\mathbf{1}$ & $\mathbf{1}$ \\
\hline $\mathbf{8}$ & $\mathbf{5 8 0}$ & $\mathbf{0}$ & $\mathbf{1}$ & $\mathbf{1}$ \\
\hline $\mathbf{9}$ & $\mathbf{5 2 0}$ & $\mathbf{0}$ & $\mathbf{0}$ & $\mathbf{1}$ \\
\hline $\mathbf{1 0}$ & $\mathbf{5 0 0}$ & $\mathbf{1}$ & $\mathbf{1}$ & $\mathbf{0}$ \\
\hline 11 & $\mathbf{4 5 0}$ & $\mathbf{0}$ & $\mathbf{0}$ & $\mathbf{1}$ \\
\hline 12 & $\mathbf{3 5 0}$ & $\mathbf{1}$ & $\mathbf{0}$ & $\mathbf{1}$ \\
\hline 13 & $\mathbf{3 0 0}$ & $\mathbf{0}$ & $\mathbf{0}$ & $\mathbf{1}$ \\
\hline 14 & $\mathbf{2 0 0}$ & $\mathbf{1}$ & $\mathbf{0}$ & $\mathbf{1}$ \\
\hline
\end{tabular}

Table (12): Survey of RAPD Markers using primer (OPM-17).

\begin{tabular}{|c|c|c|c|c|}
\hline & & \multicolumn{3}{|c|}{ OPC - 11 } \\
\hline No. & & & & \\
& M & 1 & 2 & 3 \\
\hline 1 & 1100 & 1 & 1 & 1 \\
\hline 2 & 1000 & 0 & 0 & 1 \\
\hline 3 & 900 & 1 & 1 & 1 \\
\hline 4 & $\mathbf{8 0 0}$ & 1 & 1 & 1 \\
\hline 5 & 750 & 0 & 1 & 0 \\
\hline 6 & 700 & 1 & 0 & 1 \\
\hline 7 & 600 & 1 & 1 & 1 \\
\hline 8 & 500 & 0 & 0 & 1 \\
\hline 9 & 470 & 1 & 1 & 1 \\
\hline 10 & 400 & 1 & 1 & 1 \\
\hline 11 & 370 & 0 & 0 & 1 \\
\hline 12 & 350 & 1 & 1 & 1 \\
\hline 13 & 300 & 0 & 1 & 0 \\
\hline 14 & 270 & 1 & 1 & 1 \\
\hline 15 & 250 & 1 & 1 & 0 \\
\hline 16 & 220 & 1 & 1 & 0 \\
\hline & & & & \\
\hline
\end{tabular}

\begin{tabular}{|c|c|c|c|c|}
\hline & & \multicolumn{3}{|c|}{ OP:A09 } \\
\hline No. & M & 1 & 2 & 3 \\
\hline 1 & 1500 & 0 & 0 & 1 \\
\hline 2 & 1300 & 0 & 0 & 1 \\
\hline 3 & 1000 & 1 & 1 & 1 \\
\hline 4 & 900 & 0 & 0 & 1 \\
\hline 5 & 300 & 0 & 1 & 1 \\
\hline 6 & 750 & 1 & 1 & 1 \\
\hline 7 & 700 & 0 & 0 & 1 \\
\hline 8 & 680 & 1 & 1 & 1 \\
\hline 9 & 550 & 1 & 1 & 1 \\
\hline 10 & 500 & 0 & 0 & 1 \\
\hline 11 & 430 & 0 & 0 & 1 \\
\hline 12 & 380 & 1 & 1 & 1 \\
\hline 13 & 370 & 0 & 1 & 0 \\
\hline 14 & 350 & 1 & 0 & 1 \\
\hline 15 & 320 & 1 & 1 & 1 \\
\hline 16 & 300 & 0 & 1 & 0 \\
\hline 17 & 250 & 1 & 1 & 1 \\
\hline
\end{tabular}

Table (13): Survey of RAPD Markers using primer (OPC-11).

Table (14): Survey of RAPD Markers using primer (OPA-9). 


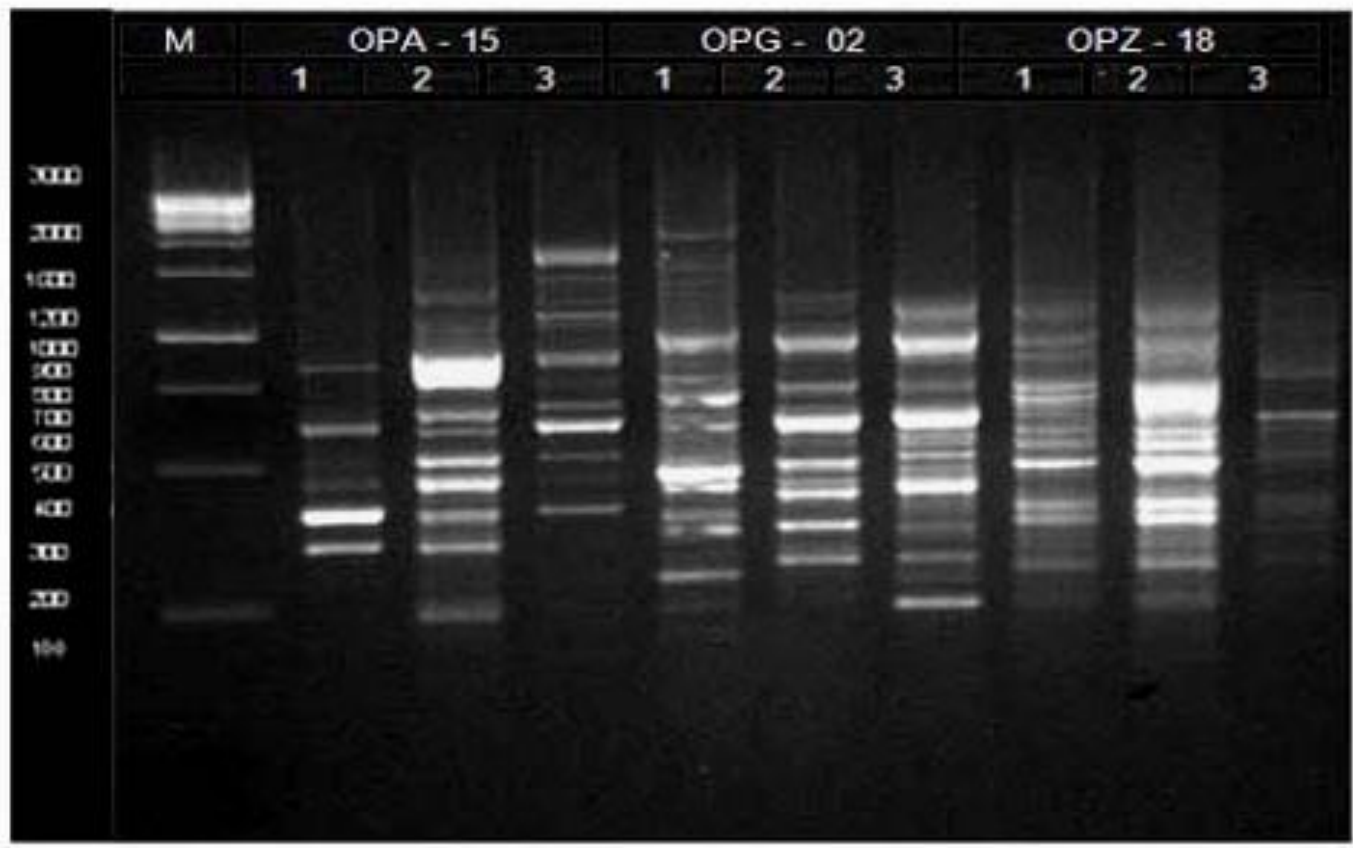

Fig (8): Agarose-gel electrophoresis products generated with primers OPA-15, OPG-02 and OPZ-18.

\begin{tabular}{|c|c|c|c|c|}
\hline & & \multicolumn{3}{|c|}{ OP:A15 } \\
\hline No. & $\mathbf{M}$ & 1 & 2 & 3 \\
\hline 1 & 1500 & 0 & 1 & 1 \\
\hline 2 & 1400 & 0 & $\mathbf{0}$ & 1 \\
\hline 3 & 1300 & 0 & 1 & 0 \\
\hline 4 & 1200 & 0 & $\mathbf{0}$ & 1 \\
\hline 5 & 1100 & 0 & $\mathbf{0}$ & 1 \\
\hline 6 & 1000 & 0 & 1 & 1 \\
\hline 7 & $\mathbf{8 3 0}$ & 1 & 1 & 1 \\
\hline 8 & $\mathbf{8 0 0}$ & 0 & 1 & 1 \\
\hline 9 & 750 & $\mathbf{0}$ & 1 & 0 \\
\hline 10 & 700 & 0 & 1 & 0 \\
\hline 11 & 660 & 1 & $\mathbf{0}$ & 1 \\
\hline 12 & 640 & 0 & 1 & $\mathbf{0}$ \\
\hline 13 & 610 & 1 & 1 & 1 \\
\hline 14 & 500 & 1 & 1 & 1 \\
\hline 15 & 450 & 1 & 1 & 1 \\
\hline 16 & 400 & 1 & 1 & 1 \\
\hline 17 & 300 & 1 & 1 & 0 \\
\hline 18 & 250 & 0 & 1 & $\mathbf{0}$ \\
\hline 19 & 230 & 0 & 1 & 0 \\
\hline
\end{tabular}

Table (15): Survey of RAPD Markers using primer (OPA-15). 


\begin{tabular}{|c|c|c|c|c|}
\hline & & \multicolumn{3}{|c|}{ OP:G02 } \\
\hline No. & $\mathbf{M}$ & 1 & 2 & 3 \\
\hline 1 & 3000 & 1 & 0 & 0 \\
\hline 2 & 2500 & 1 & 0 & 0 \\
\hline 3 & 1300 & 0 & 1 & 0 \\
\hline 4 & 1200 & 0 & 1 & 1 \\
\hline 5 & 1150 & 0 & 0 & 1 \\
\hline 6 & 1100 & 0 & 1 & 0 \\
\hline 7 & 1000 & 1 & 1 & 1 \\
\hline 8 & 950 & 1 & 0 & 1 \\
\hline 9 & 850 & 1 & 0 & 0 \\
\hline 10 & 750 & 1 & 1 & 1 \\
\hline 11 & 650 & 1 & 1 & 1 \\
\hline 12 & 550 & 1 & 1 & 1 \\
\hline 13 & 500 & 0 & 0 & 1 \\
\hline 14 & 480 & 0 & 1 & 1 \\
\hline 15 & 450 & 1 & 1 & 0 \\
\hline 16 & 430 & 0 & 1 & 1 \\
\hline 17 & 400 & 1 & 0 & 0 \\
\hline 18 & 350 & 1 & 1 & 1 \\
\hline 19 & 300 & 0 & 1 & 1 \\
\hline 20 & 280 & 1 & 0 & 1 \\
\hline 21 & 250 & 1 & 0 & 1 \\
\hline
\end{tabular}

Table (16): Survey of RAPD Markers using primer (OPG-02).

\begin{tabular}{|c|c|c|c|c|}
\hline & & \multicolumn{3}{|c|}{ OP: Z18 } \\
\hline No. & M & 1 & 2 & 3 \\
\hline 1 & 1300 & 1 & 0 & 1 \\
\hline 2 & 1200 & 1 & 1 & 0 \\
\hline 3 & 1000 & 1 & 1 & 0 \\
\hline 4 & 850 & 1 & 1 & 0 \\
\hline 5 & 800 & 1 & 1 & 1 \\
\hline 6 & 750 & 1 & 1 & 0 \\
\hline 7 & 700 & 0 & 0 & 1 \\
\hline 8 & 650 & 1 & 1 & 1 \\
\hline 9 & 600 & 1 & 1 & 0 \\
\hline 10 & 550 & 1 & 1 & 1 \\
\hline 11 & 460 & 1 & 1 & 1 \\
\hline 12 & 430 & 1 & 1 & 1 \\
\hline 13 & 380 & 0 & 0 & 1 \\
\hline 14 & 350 & 0 & 1 & 0 \\
\hline 15 & 300 & 1 & 1 & 1 \\
\hline 16 & 250 & 1 & 1 & 0 \\
\hline
\end{tabular}

Table (17): Survey of RAPD Markers using primer (OPZ-18).

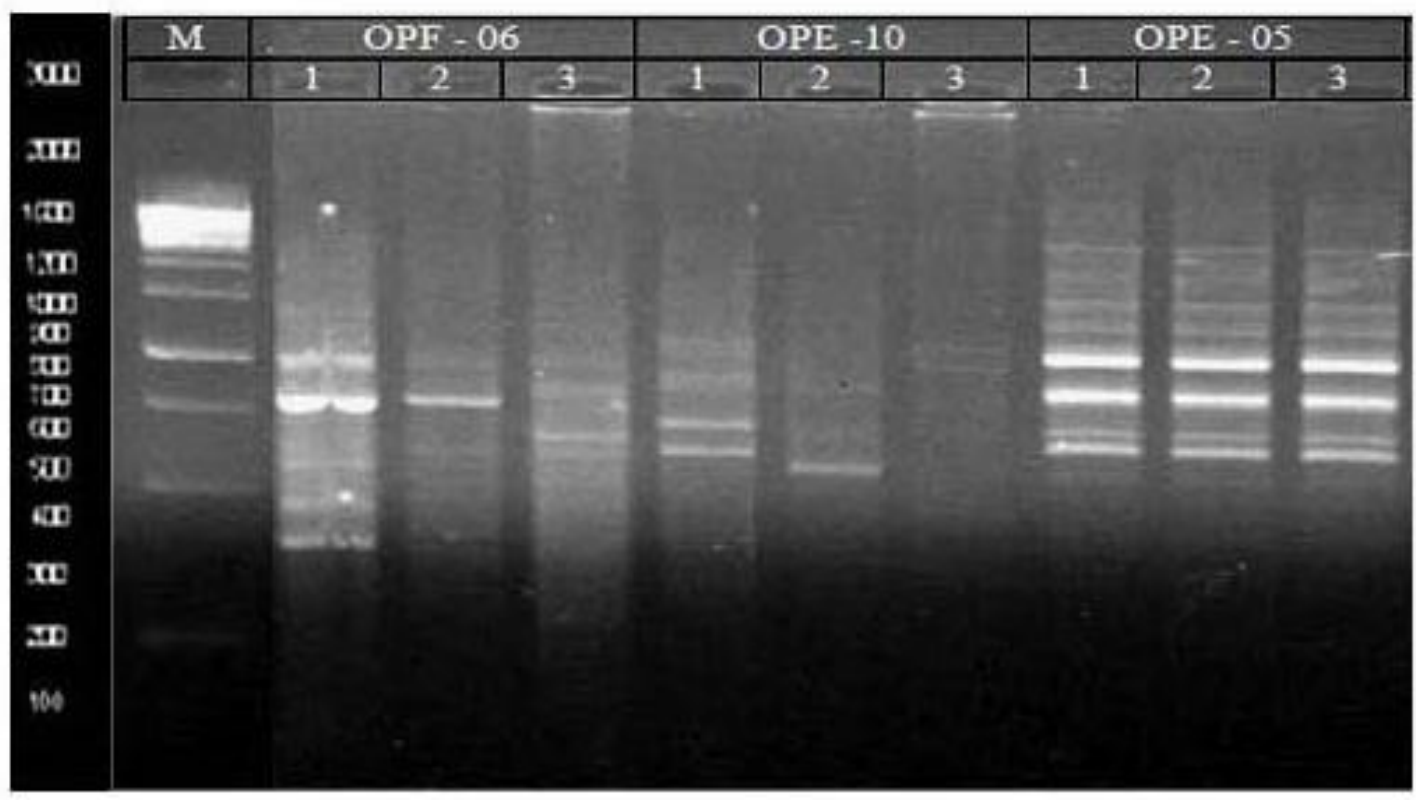

Fig (9): Agarose-gel electrophoresis products generated with primers OPF-6, OPE-10 and OPE-05. 


\begin{tabular}{|c|c|c|c|c|}
\hline & & \multicolumn{3}{|c|}{ OP:F06 } \\
\hline No. & M & 1 & 2 & 3 \\
\hline 1 & 1200 & 1 & 0 & 1 \\
\hline 2 & 900 & 1 & 1 & 1 \\
\hline 3 & 750 & 1 & 1 & 1 \\
\hline 4 & 600 & 0 & 0 & 1 \\
\hline 5 & 550 & 1 & 1 & 1 \\
\hline 6 & 530 & 1 & 0 & 0 \\
\hline 7 & 450 & 1 & 0 & 0 \\
\hline 8 & 400 & 1 & 0 & 0 \\
\hline
\end{tabular}

Table (18): Survey of RAPD Markers using primer (OPF-6).

\begin{tabular}{|c|c|c|c|c|}
\hline & & \multicolumn{3}{|c|}{ OPE -10 } \\
\hline No. & M & $\mathbf{1}$ & $\mathbf{2}$ & $\mathbf{3}$ \\
\hline $\mathbf{1}$ & $\mathbf{1 1 0 0}$ & $\mathbf{0}$ & $\mathbf{1}$ & $\mathbf{0}$ \\
\hline $\mathbf{2}$ & $\mathbf{1 0 0 0}$ & $\mathbf{1}$ & $\mathbf{0}$ & $\mathbf{0}$ \\
\hline $\mathbf{3}$ & $\mathbf{8 0 0}$ & $\mathbf{1}$ & $\mathbf{1}$ & $\mathbf{1}$ \\
\hline $\mathbf{4}$ & $\mathbf{6 0 0}$ & $\mathbf{0}$ & $\mathbf{1}$ & $\mathbf{0}$ \\
\hline $\mathbf{5}$ & $\mathbf{5 8 0}$ & $\mathbf{1}$ & $\mathbf{0}$ & $\mathbf{0}$ \\
\hline $\mathbf{6}$ & $\mathbf{5 3 0}$ & $\mathbf{1}$ & $\mathbf{1}$ & $\mathbf{0}$ \\
\hline $\mathbf{7}$ & $\mathbf{5 2 0}$ & $\mathbf{0}$ & $\mathbf{0}$ & $\mathbf{1}$ \\
\hline
\end{tabular}

Table (19): Survey of RAPD Markers using primer (OPE-10).

\begin{tabular}{|c|c|c|c|c|}
\hline & & \multicolumn{3}{|c|}{ OPE - 05 } \\
\hline No. & M & 1 & 2 & 3 \\
\hline 1 & 2000 & 1 & 1 & 1 \\
\hline 2 & 1500 & 1 & 0 & 0 \\
\hline 3 & 1300 & 1 & 1 & 1 \\
\hline 4 & 1050 & 1 & 1 & 1 \\
\hline 5 & 900 & 1 & 1 & 1 \\
\hline 6 & 750 & 1 & 1 & 1 \\
\hline 7 & $\mathbf{6 2 0}$ & 1 & 1 & 1 \\
\hline 8 & 590 & 1 & 1 & 1 \\
\hline 9 & 520 & 1 & 1 & 1 \\
\hline
\end{tabular}

Table (20): Survey of RAPD Markers using primer (OPE-05).

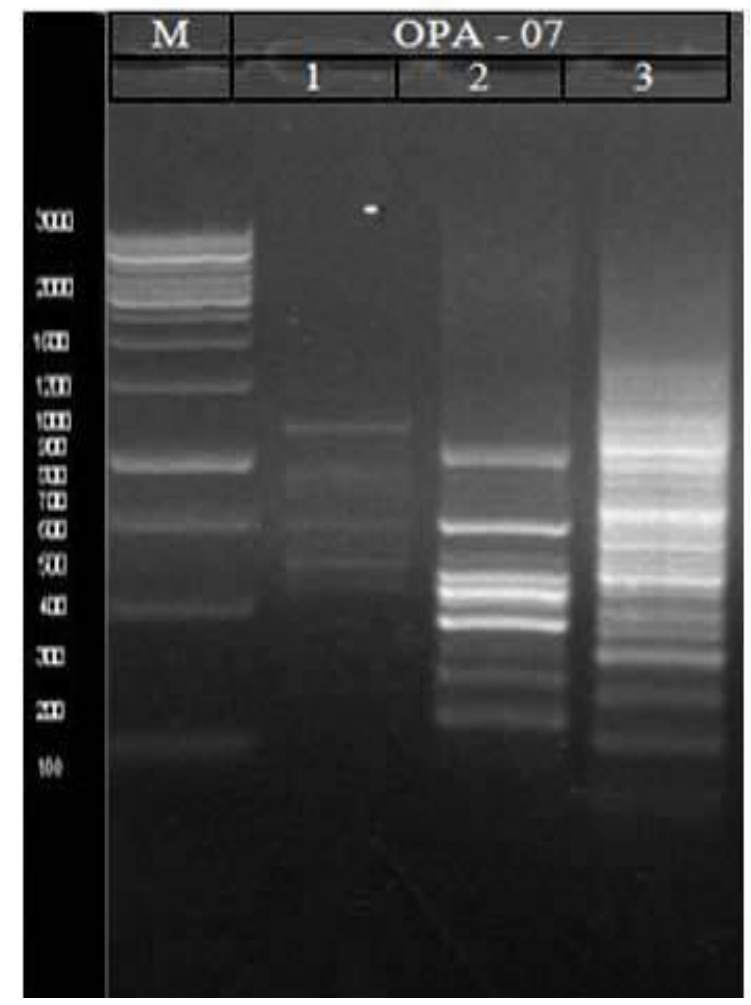

\begin{tabular}{|c|c|c|c|c|}
\hline & & \multicolumn{3}{|c|}{ OPA - 07 } \\
\hline No. & M & $\mathbf{1}$ & $\mathbf{2}$ & $\mathbf{3}$ \\
\hline $\mathbf{1}$ & $\mathbf{1 5 0 0}$ & $\mathbf{0}$ & $\mathbf{0}$ & $\mathbf{1}$ \\
\hline $\mathbf{2}$ & $\mathbf{1 2 0 0}$ & $\mathbf{1}$ & $\mathbf{0}$ & $\mathbf{1}$ \\
\hline $\mathbf{3}$ & $\mathbf{1 1 0 0}$ & $\mathbf{0}$ & $\mathbf{0}$ & $\mathbf{1}$ \\
\hline $\mathbf{4}$ & $\mathbf{1 0 5 0}$ & $\mathbf{0}$ & $\mathbf{1}$ & $\mathbf{1}$ \\
\hline $\mathbf{5}$ & $\mathbf{9 5 0}$ & $\mathbf{1}$ & $\mathbf{0}$ & $\mathbf{1}$ \\
\hline $\mathbf{6}$ & $\mathbf{8 5 0}$ & $\mathbf{0}$ & $\mathbf{0}$ & $\mathbf{1}$ \\
\hline 7 & $\mathbf{7 5 0}$ & $\mathbf{1}$ & $\mathbf{1}$ & $\mathbf{1}$ \\
\hline $\mathbf{8}$ & $\mathbf{7 0 0}$ & $\mathbf{0}$ & $\mathbf{0}$ & $\mathbf{1}$ \\
\hline $\mathbf{9}$ & $\mathbf{6 0 0}$ & $\mathbf{1}$ & $\mathbf{1}$ & $\mathbf{1}$ \\
\hline 10 & $\mathbf{5 5 0}$ & $\mathbf{0}$ & $\mathbf{1}$ & $\mathbf{1}$ \\
\hline 11 & $\mathbf{5 2 0}$ & $\mathbf{1}$ & $\mathbf{0}$ & $\mathbf{1}$ \\
\hline 12 & $\mathbf{5 0 0}$ & $\mathbf{0}$ & $\mathbf{1}$ & $\mathbf{0}$ \\
\hline 13 & $\mathbf{4 8 0}$ & $\mathbf{0}$ & $\mathbf{0}$ & $\mathbf{1}$ \\
\hline 14 & $\mathbf{4 5 0}$ & $\mathbf{0}$ & $\mathbf{1}$ & $\mathbf{1}$ \\
\hline 15 & 400 & $\mathbf{0}$ & $\mathbf{1}$ & $\mathbf{1}$ \\
\hline 16 & $\mathbf{3 5 0}$ & $\mathbf{0}$ & $\mathbf{1}$ & $\mathbf{1}$ \\
\hline 17 & $\mathbf{3 0 0}$ & $\mathbf{0}$ & $\mathbf{1}$ & $\mathbf{1}$ \\
\hline 18 & 230 & $\mathbf{0}$ & $\mathbf{0}$ & $\mathbf{1}$ \\
\hline
\end{tabular}

Table (21): Survey of RAPD Markers using primer (OPA-7).

Fig (10): Agarose-gel electrophoresis products generated with primers OPA-7. 
Table (22): Number of amplified and polymorphic DNA - fragments in Schilbe mystus, Schilbe uranoscopus and Siluranodon auritus.

\begin{tabular}{|c|c|c|c|c|c|c|c|}
\hline \multirow{2}{*}{ No. } & \multirow{2}{*}{ Primer code } & \multirow{2}{*}{$\begin{array}{c}\text { Total of } \\
\text { amplified } \\
\text { bands (a) }\end{array}$} & \multicolumn{3}{|c|}{ No. of amplified bands } & \multirow{2}{*}{$\begin{array}{l}\text { No. of } \\
\text { Common } \\
\text { bands }\end{array}$} & \multirow{2}{*}{$\begin{array}{c}\text { No. of } \\
\text { polymorphic } \\
\text { bands (b) }\end{array}$} \\
\hline & & & $\begin{array}{l}\text { Schilbe } \\
\text { mystus }\end{array}$ & $\begin{array}{c}\text { Schilbe } \\
\text { uranoscopus }\end{array}$ & $\begin{array}{c}\text { Siluranodon } \\
\text { auritus }\end{array}$ & & \\
\hline 1 & OPA - 4 & 14 & 1 & 9 & 11 & 1 & 13 \\
\hline 2 & OPA - 17 & 15 & 7 & 10 & 11 & 4 & 11 \\
\hline 3 & OPB - 17 & 15 & 12 & 12 & 11 & 8 & 7 \\
\hline 4 & OPB - 6 & 13 & 4 & 7 & 10 & 2 & 11 \\
\hline 5 & OPC - 1 & 17 & 13 & 13 & 9 & 6 & 11 \\
\hline 6 & OPC - 18 & 11 & 7 & 8 & 7 & 4 & 7 \\
\hline 7 & OPD - 5 & 11 & 10 & 7 & 9 & 5 & 6 \\
\hline 8 & OPE - 6 & 18 & 14 & 15 & 12 & 9 & 9 \\
\hline 9 & OPM - 2 & 16 & 9 & 8 & 13 & 4 & 12 \\
\hline 10 & OPM - 5 & 20 & 14 & 12 & 10 & 6 & 14 \\
\hline 11 & OPC - 11 & 16 & 11 & 12 & 12 & 8 & 8 \\
\hline 12 & OPM - 17 & 14 & 6 & 6 & 13 & 3 & 11 \\
\hline 13 & OPA - 9 & 17 & 8 & 10 & 15 & 7 & 10 \\
\hline 14 & OPA - 15 & 19 & 7 & 15 & 12 & 5 & 14 \\
\hline 15 & OPG - 2 & 21 & 13 & 12 & 14 & 5 & 16 \\
\hline 16 & OPZ - 18 & 16 & 13 & 13 & 9 & 6 & 10 \\
\hline 17 & OPF - 6 & 8 & 7 & 3 & 5 & 3 & 5 \\
\hline 18 & OPE - 10 & 7 & 4 & 4 & 2 & 1 & 6 \\
\hline 19 & OPE - 5 & 9 & 9 & 8 & 8 & 8 & 1 \\
\hline 20 & OPA - 7 & 18 & 5 & 9 & 17 & 2 & 16 \\
\hline Total & & 295 & 174 & 193 & 210 & 97 & 198 \\
\hline
\end{tabular}

Table (23): Genetic similarity values calculated from the DNA fragments amplified from Schilbe mystus, Schilbe uranoscopus and Siluranodon auritus using twenty OPERON primers.

\begin{tabular}{|c|c|c|l|}
\hline $\begin{array}{c}\text { Siluranodon } \\
\text { auritus }\end{array}$ & $\begin{array}{c}\text { Schilbe } \\
\text { uranoscopus }\end{array}$ & $\begin{array}{c}\text { Schilbe } \\
\text { mystus }\end{array}$ & \\
\hline & & 100 & Schilbe mystus \\
\hline & 100 & 73 & Schilbe uranoscopus \\
\hline 100 & 60.8 & 64.1 & Siluranodon auritus \\
\hline
\end{tabular}




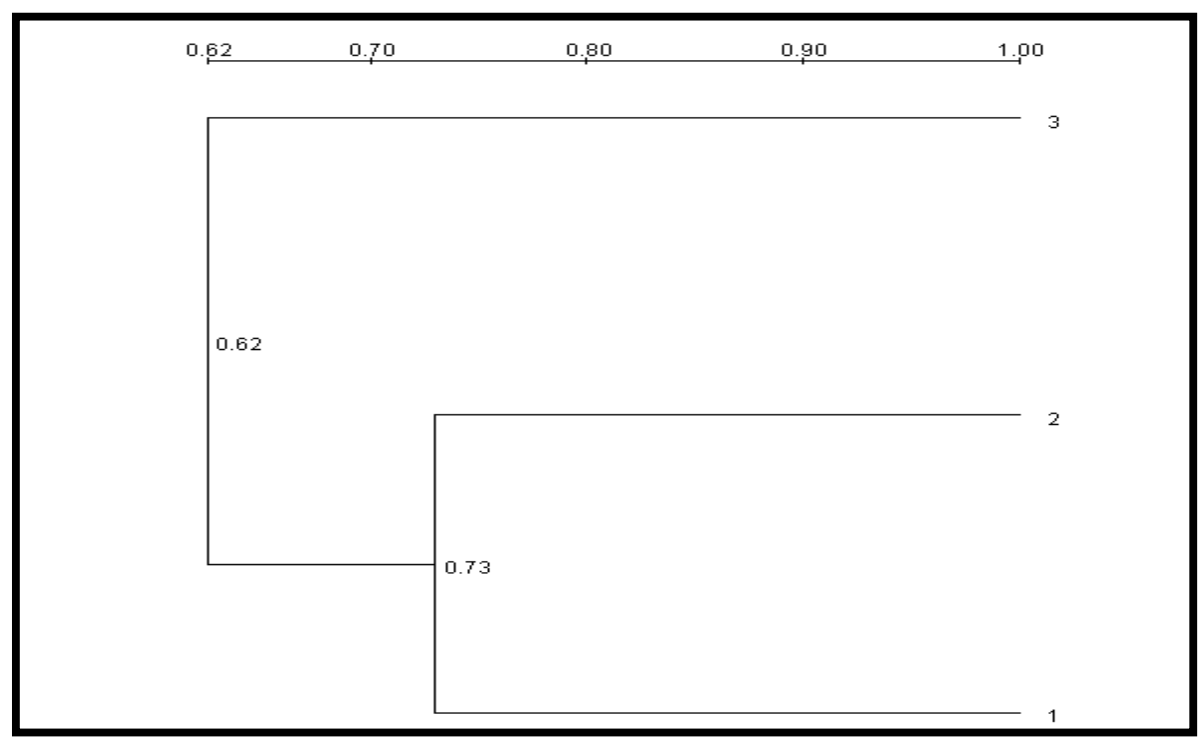

Fig. (11): Dendrogram demonstrating the relationship among Schilbe mystus, Schilbe uranoscopus and Siluranodon auritus, based on data recorded from polymorphism of RAPD markers. 1- Schilbe mystus, 2Schilbe uranoscopus and 3-Siluranodon auritus. Dendrogram consisted of two clusters; (A) contained Siluranodon auritus and (B) contained Schilbe mystus and Schilbe uranoscopus.

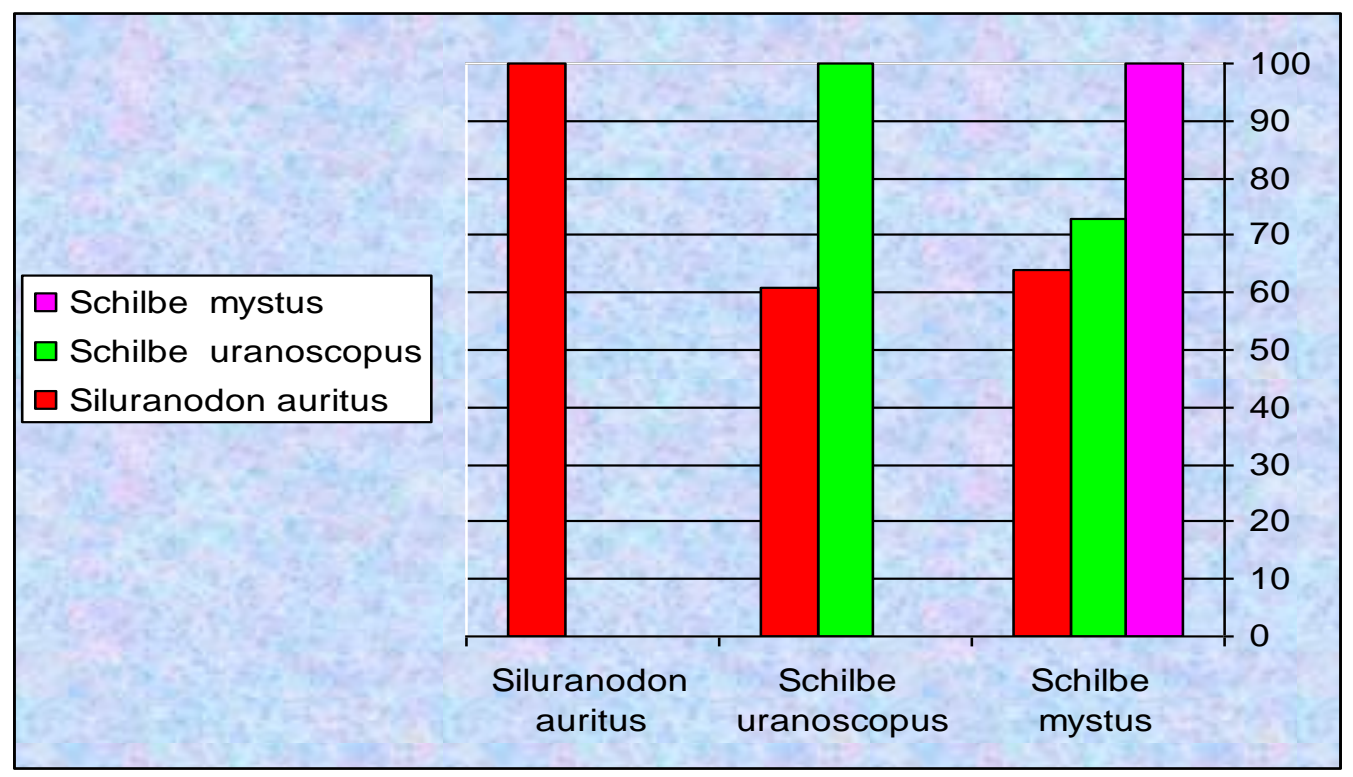

Fig. (12): Demonstrating the relationship degree among Schilbe mystus, Schilbe uranoscopus and Siluranodon auritus, based on data recorded from polymorphism of RAPD markers. 